\title{
Epidemiology of Onychomycosis in Pernambuco, Northeastern of Brazil: Results of a Laboratory-Based Survey
}

\begin{abstract}
Patrícia Cristina Rodrigues Lima ${ }^{1,2}$, Ertênia Paiva Oliveiraa ${ }^{1}$, Ana Emília de Medeiros Roberto ${ }^{1}$, Maria Daniella Silva Buonafina ${ }^{1}$, Melyna Chaves Leite de Andrade ${ }^{1}$, Vanessa Marques Barreto Pontes ${ }^{1}$, João Vitaliano de Carvalho Rocha $^{2}$, Rejane Pereira Neves ${ }^{1}$, Humberto Gonçalves Bertão ${ }^{3}$ and Reginaldo Gonçalves de Lima Neto ${ }^{1,3,4 *}$
\end{abstract}

${ }^{1}$ Department of Mycology, Federal University of Pernambuco, Brazil

${ }^{2}$ Professor of the Aesthetics and Cosmetics graduation of the Integrated College of Pernambuco, Brazil

${ }^{3}$ Postgraduate Program in Pathology, Federal University of Pernambuco, Brazil

${ }^{4}$ Department of Tropical Medicine, Federal University of Pernambuco, Brazil

*Corresponding author: Reginaldo Gonçalves de Lima Neto, Laboratory of Medical Mycology, Department of Mycology, Federal University of Pernambuco, Recife, Brazil

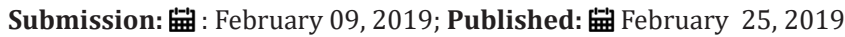

\begin{abstract}
Onychomycosis is chronic ungual disease that affects people worldwide and whose prevalence has been increasing in recent decades. Among the etiological agents are yeasts, dermatophytes and non-dermatophytid filamentous fungi (NDFF). The symptoms and severity can vary widely according to the anatomic site, condition of the individual and geographic location. Laboratory identification of the fungal etiological agents is necessary due to the wide variety of these agents and the varied responses to the existing drugs. This study aimed to diagnose and characterize epidemiologically onychomycosis, besides of to determine the susceptibility profile against evaluable antifungals drugs. Patients of a Dermatological Public Service of reference at Recife city, Northeast of the Brazil, which were suffering from suggestive lesions were evaluated between August 2016 and July 2017. Mycological diagnosis was carried out by direct microscopic examination of clinical samples clarified with $20 \%$ potassium hydrochloride (KOH) and by culture in Sabouraud dextrose agar medium supplemented with $2 \%$ (v/v) chloramphenicol. After incubation for 15 days at $35-37{ }^{\circ} \mathrm{C}$, the macro and microscopic aspects of the colonies were analyzed for specie identification. The yeasts were identified by proteomic analysis with MALDI-TOF MS. In vitro antifungal susceptibility testing was carried out according CLSI method. Signs and symptoms suggestive of onychomycosis were presented in 196 patients, of which were obtained 224 nail samples. In the mycological tests, 119 samples from 108 patients were diagnosed positively for onychomycosis, of them 77 (39.28\%) from females, and the hand (fingernails) was the region most often affected, with 61 cases (31.12\%). The etiological agents isolated most frequently were yeasts of Candida with 92 cases (77.31\%), followed by non-dermatophytic fungi with 19 cases (15.97\%), especially the genus Fusarium with 17 cases (14.28\%), and dermatophytes with 8 cases (6.72\%). Candida yeasts were the most prevalent etiological agents and the area most affected was the hand, associated with homemakers, who typically have greater contact with humidity. Onychomycosis caused by dermatophytes was least frequent, however terbinafine was the drug of choice for therapy in patients and in vitro more effective against dermatophytes. Most of the patients had been submitted to ineffective treatment. The yeasts were more susceptible to the antifungals and NDFF were the more resistant to the antifungals. The prescription of drug combinations can be a solution for treatment of onychomycosis caused by NDFF. The patients' reports of longstanding symptoms indicate the chronic nature of the disease and the profile can change frequently, suggesting that periodic analyses are necessary. The frequent recurrences can be related to the high cost and long treatment periods, while public awareness campaigns can help to reduce infection rates..
\end{abstract}

Keywords: Nail disease; Superficial mycoses; Diagnosis; Susceptibility

\section{Introduction}

Onychomycosis is a disease that affects the finger and toenails, of both men and women, but is infrequently found in children. The etiological agents are yeasts, dermatophytes and non-dermatophytic filamentous fungi (NDFF). In recent decades the number of cases of onychomycosis has been rising, due to population growth and extensive therapies with antibiotics and corticoids [1-3]. The clinical aspect of onychomycosis can vary among hyperkeratosis, change in nail color and distal detachment of the nail plate, and it can be misdiagnosed as other diseases, such as paronychia, psoriasis and lichen planus [4]. 
Onychomycosis causes problems such as low self-esteem, reduced functional capacity and impairment of daily activities [5]. The disease develops based on predisposing factors, such as nail deformities, poor dress and cleanliness habits, diabetes, genetic predisposition, angiopathy and immunosuppression once immunosuppressed individuals have higher rates than immunocompetent people [6]. Studies conducted in various countries have indicated the presence of onychomycosis throughout the world, observing aspects such as demographics (age range, sex), cultural habits and geographic distribution [7-10]. Herein the objective was to diagnose and characterize onychomycosis among patients of a public referral dermatology service in northeastern Brazil. Moreover, the susceptibility profile of the clinical isolates against antifungal drugs used in onychomycosis` therapy were evaluated.

\section{Methods}

\section{Type and site of study}

A prospective study with observational approach was developed in the period between August 2016 and July 2017 involving incidence description of onychomycosis by analysis of laboratory results. Nail samples were collected from patients with lesions suggestive of onychomycosis at a public dermatology service of the Clinical Hospital of Federal University of Pernambuco (UFPE), Brazil. At the same time, questionnaires were answered by the patients. The diagnosis was performed in the Medical Mycology Laboratory of the Biosciences Center of UFPE.

\section{Mycological procedures}

The samples for mycological diagnosis was obtained by scraping of the nail plate with a sterile scalpel and maintained in sterile dishes for direct examination followed by culturing. To observe possible fungal structures, the samples were mounted on slides with $20 \% \mathrm{KOH}$ and examined under a light microscope. Other samples of the same material were inoculated on Sabouraud dextrose agar supplemented with 50mg/L of chloramphenicol and kept at an average temperature of $35-37^{\circ} \mathrm{C}$ for up to four weeks. The colonies were identified by traditional taxonomy according to the macro and microscopic characteristics. Additionally, the yeasts isolated were submitted to protein extraction for examination by MALDI-TOF mass spectrometry [11]. The purified isolates were evaluated in vitro by antifungal susceptibility testing (AST) by the broth dilution method [12].

\section{Statistical analyses}

Social-demographic, laboratory and clinical data obtained from patients were analyzed with Graphpad Prism version 6.0 (San Diego, CA, USA) software. Categorical variables were analyzed by Fisher's exact test.

\section{Research ethical aspects}

This study was submitted and approved by the Human Research Ethics Committee of the Health Sciences Centre (CCS) of Federal University of Pernambuco (UFPE) under CAAE number 57861816.4.0000.5208, integrally following the ethical principles established under the resolution $466 / 12$ of the National Council of Health (CNS). All data was collected and filed after CPE approval, all information was used exclusively in the present study, and individuals' identities were maintained in absolute secrecy.

\section{Results}

\section{Causative agents}

The laboratory-based diagnosis showed that 108 patients (55.1\%) had onychomycosis, 77 of them women and 31 men. The ages of all the patients ranged from 10 to 94 years, while the average age of those with conclusive diagnosis of onychomycosis was 59 years. Figure 1 shows the histogram of the age ranges of the positive patients in 11-year intervals. Fingernails were most frequent affected region, closely followed by toenails, while five patients only presented both regions affected.

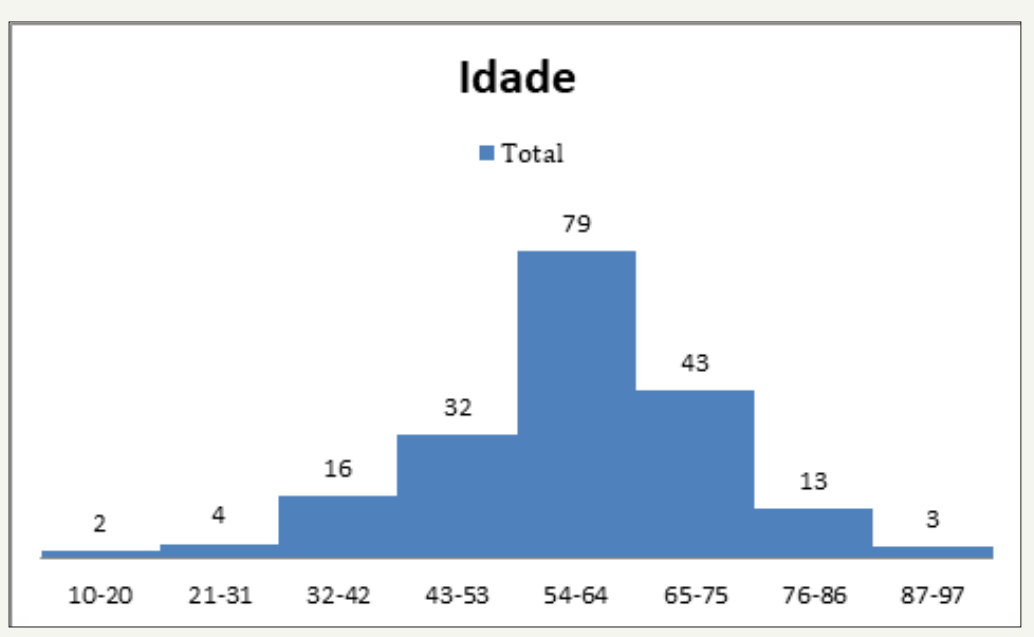

Figure 1: Histogram of the age range frequencies. 
Candida species were most prevalent and isolated in 92 samples (77.31\%), however 28 clinical yeasts only were identified and had AST carried out. Candida proteomic analysis by MALDI-TOF MS identified C. albicans (4), C. parapsilosis (12), C. tropicalis (8), and C. orthopsilosis (4). NDFF were isolated in 19 samples (15.97\%), where 17 were of genus Fusarium sp, one Aspergillus niger and one Scytalidium dimidiatum. Two patients were diagnosed with onychomycosis by Candida associated with Fusarium. Dermatophytes were identified in eight (6.72\%) samples being entirely of genus Trichophyton.

Among the variables analyzed by Fisher's exact test, three interactions were significant, namely: profession/sex $(p<0.001)$, etiological agent/sex $(p=0.001)$ and affected region/sex $(p=0.001)$. The most frequent occupation reported by the patients was homemaker, all of them women. Regarding etiological agent and affected area, the greatest incidence of Candida isolated were on the fingernails. For toenails, the largest prevalence was Candida sp., followed by Fusarium sp., Trichophyton sp., Aspergillus sp. and Scytalidium sp., while the only etiological agent affecting both the toenails and fingernails was Candida $s p$.

\section{Antifungal profile}

Twenty-eight Candida isolated, eight NDFF and four dermatophytes had antifungal profile obtained by CLSI method. The MIC values are summarized in (Table 1). The four dermatophytes isolated showed minimum inhibitory concentration (MIC) for terbinafine lower than $0.125 \mu \mathrm{g} / \mathrm{mL}$ (susceptible), while two T. mentagrophytes isolates presented high MIC values for ketoconazole, itraconazole and fluconazole, and was classified as resistant. Others two T. mentagrophytes isolate presented the lowest MIC values and was classified as susceptible against four antifungal drugs (Table 2). The same drugs evaluated against dermatophytes were used with eight NDFF. Scytalidium dimidiatum was susceptible against ketoconazole, while the other NDFF seven isolates presented higher concentrations, indicating resistance. Two NDFF isolates were fluconazole-susceptible with MIC of $32 \mu \mathrm{g} /$ $\mathrm{mL}$, while four isolates presented MIC values equal or greater than $64 \mu \mathrm{g} / \mathrm{mL}$. The sensitivity profile of NDFF against itraconazole was $16 \mu \mathrm{g} / \mathrm{mL}$ for four isolates and higher than $16 \mu \mathrm{g} / \mathrm{mL}$ for others four isolates displaying resistance (Figure 2).

Table 1: In vitro antifungal susceptibility of Candida sp. isolated from nail scrapings from patients of a public health service unit.

\begin{tabular}{|c|c|c|c|c|c|}
\hline \multirow{2}{*}{ Patient ID number } & \multirow{2}{*}{ Species } & \multicolumn{4}{|c|}{$\operatorname{MIC}(\mu \mathrm{g} / \mathrm{mL})$} \\
\hline & & Ketoconazole & Fluconazole & Itraconazole & Ciclopirox \\
\hline 36 & C. parapsilosis & (S) 0.25 & (S)2 & (S) 0.03125 & 0.5 \\
\hline $37 \mathrm{~A}$ & C. parapsilosis & (S) 0.125 & $(\mathrm{~S}) 2$ & (R)16 & 0.25 \\
\hline 79 & C. tropicalis & (S) 0.03125 & (S) 0.125 & (R)1 & 2 \\
\hline 103 & C. parapsilosis & (S)0.0625 & (S)1 & (S) 0.0625 & 0.5 \\
\hline 120 & C. parapsilosis & $(\mathrm{R}) 16$ & $(\mathrm{~S}) 0.5$ & (S) 0.125 & 0.5 \\
\hline 167 & C. tropicalis & $(\mathrm{S}) 1$ & $(\mathrm{R}) 8$ & (R)1 & 1 \\
\hline 185 & C.tropicalis & $(\mathrm{S}) 8$ & (R)16 & (R)16 & 0.5 \\
\hline 185B & C.parapsilosis & (S)0.0625 & $(\mathrm{S}) 2$ & (DDS)0.5 & 1 \\
\hline 191 & C.albicans & $(\mathrm{S}) 8$ & (S) 0.125 & (R)16 & 0.25 \\
\hline 192 & C.tropicalis & $(\mathrm{S}) 2$ & (R)64 & (R)16 & 0.5 \\
\hline 198 & C. albicans & (S) 0.03125 & (S)0.5 & (S) 0.125 & 0.25 \\
\hline 200 & C. parapsilosis & (S) 0.03125 & (S) 0.25 & (DDS) 0.25 & 0.25 \\
\hline 206 & C.parapsilosis & (S)0.125 & (S)0.5 & (R)4 & 2 \\
\hline 239 & C. tropicalis & (S)1 & (R) 64 & (R)16 & 0.25 \\
\hline 266 & C. tropicalis & $\mathrm{R}(16)$ & $(\mathrm{S}) 0.5$ & (R)16 & 0.125 \\
\hline 273 & C. tropicalis & $(\mathrm{S}) 0.5$ & $(\mathrm{~S}) 2$ & (S)0.03125 & 0.5 \\
\hline 281 & C. parapsilosis & $(\mathrm{S}) 0.5$ & $(\mathrm{DDS}) 4$ & $(\mathrm{R}) 1$ & 0.25 \\
\hline 283 & C. orthopsilosis & (S) 0.125 & $(S) 2$ & (S) 0.125 & 0.25 \\
\hline 286 & C. tropicalis & $(\mathrm{S}) 2$ & (S)1 & (DDS)0.5 & 0.125 \\
\hline 298 & C. albicans & (S) 0.03125 & (S) 0.25 & (DDS)0.5 & 0.25 \\
\hline 299 & C. orthopsilosis & (S) 0.03125 & (S) 0.25 & (DDS) 0.25 & 1 \\
\hline 306 & C. orthopsilosis & (R)16 & (S)1 & (S) 0.125 & 0.25 \\
\hline 625 & C. parapsilosis & (S)0.25 & (R) 64 & (R)8 & 0.25 \\
\hline
\end{tabular}




\begin{tabular}{|c|c|c|c|c|c|}
\hline 628 & C. parapsilosis & $(\mathrm{S}) 0.03125$ & $(\mathrm{~S}) 0.5$ & $(\mathrm{~S}) 0.125$ & 0.25 \\
\hline 669 & C. parapsilosis & $(\mathrm{S}) 0.03125$ & $(\mathrm{~S}) 0.125$ & $(\mathrm{~S}) 0.125$ & $(\mathrm{R}) 8$ \\
\hline 698 & C. albicans & $(\mathrm{S}) 0.03125$ & $(\mathrm{~S}) 0.5$ & $(\mathrm{~S}) 0.125$ & 0.125 \\
\hline 711 & C. orthopsilosis & $(\mathrm{S}) 8$ & $(\mathrm{~S}) 0.25$ & $(\mathrm{~S})$ & 0.25 \\
\hline 843 & C. parapsilosis & $(\mathrm{S}) 0.0625$ & $(\mathrm{~S}) 2$ & $(25$ & 0.25 \\
\hline
\end{tabular}

$\mathrm{S}=$ Susceptible, DDS=Dose-dependent susceptible, $\mathrm{R}=$ Resistant. There is no specific standard for ciclopirox oxalamine, so in these cases we considered resistance to be levels equal to or greater than $1 \mu \mathrm{g} / \mathrm{mL}$.

Table 2: In vitro antifungal susceptibility of the dermatophytes isolated from nail scrapings from patients of a public health service unit.

\begin{tabular}{|c|c|c|c|c|c|}
\hline \multirow{2}{*}{ Patient ID Number } & \multirow{2}{*}{ Specie } & \multicolumn{4}{|c|}{ MIC $(\mu \mathrm{g} / \mathrm{mL})$} \\
\cline { 3 - 6 } & & Ketoconazole & Itraconazole & Fluconazole & Terbinafine \\
\hline 87 & Tricophyton mentagrophytes & 16 & 16 & 64 & $<0.125$ \\
\hline 170 & Tricophyton mentagrophytes & 16 & 16 & 64 & $<0.125$ \\
\hline 241 & Tricophyton mentagrophytes & 0.06 & 1 & $<$ & $<0.125$ \\
\hline 263 & Tricophyton mentagrophytes & $<0.03125$ & $<0.03125$ & 0.5 & $<0.125$ \\
\hline
\end{tabular}

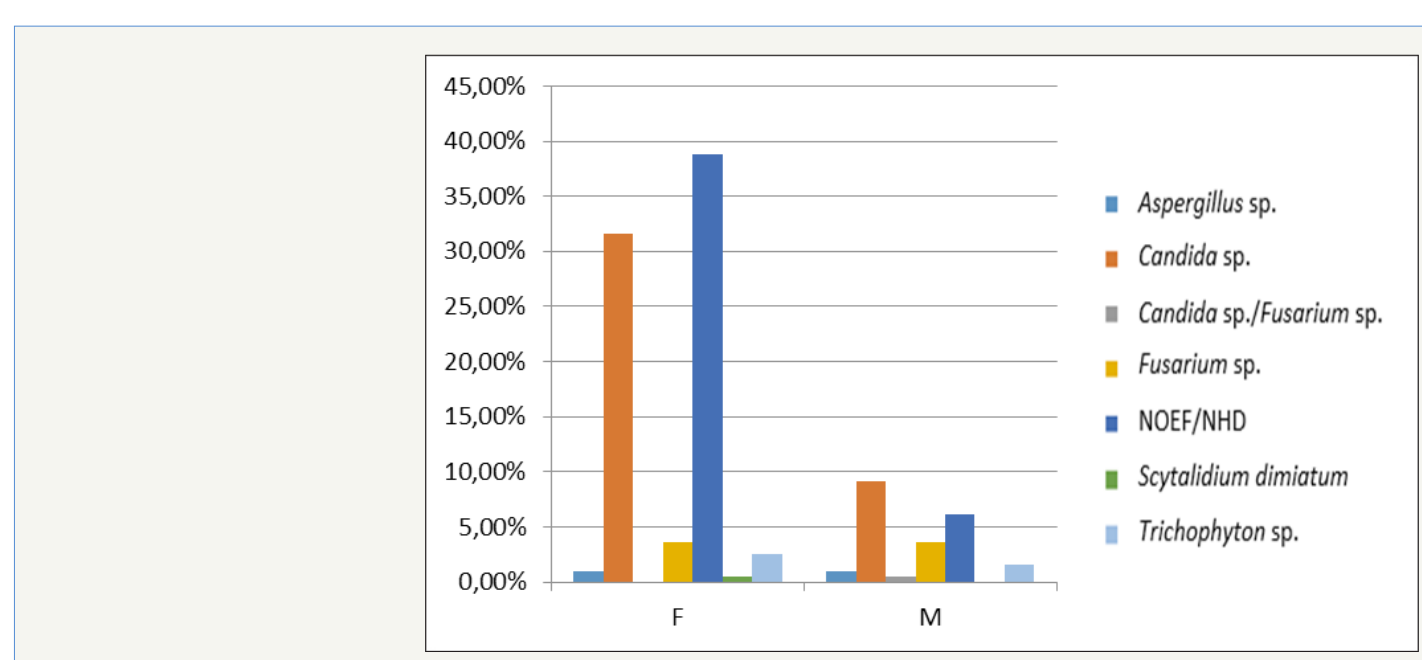

Figure 2: Bar graph of the sex/etiological agent relationship.

The drugs evaluated in the tests with yeasts were ketoconazole, fluconazole, itraconazole and ciclopirox olamine. C. parapsilosis showed MIC values between $0.03125-0.5 \mu \mathrm{g} / \mathrm{mL}$ in 11 isolated classified as susceptible to ketoconazole, while only one isolated was resistant $(16 \mu \mathrm{g} / \mathrm{mL})$. Ten isolates were susceptible to fluconazole $(0.125-2 \mu \mathrm{g} / \mathrm{mL})$, one dose-dependent $(4 \mu \mathrm{g} / \mathrm{mL})$ and one resistant $(64 \mu \mathrm{g} / \mathrm{mL})$. The greatest resistance was to itraconazole, with four isolates having high MIC values $(4 \mu \mathrm{g} / \mathrm{mL}-16 \mu \mathrm{g} / \mathrm{mL})$. There are no standards for ciclopirox olamine, and the CLSI guidelines suggests resistance in MIC values greater than or equal to $1 \mu \mathrm{g} / \mathrm{mL}$. Therefore, two $C$. parapsilosis isolates were resistant to ciclopirox olamine, with MIC values of $1 \mu \mathrm{g} / \mathrm{mL}$ and $2 \mu \mathrm{g} / \mathrm{mL}$. The MIC values for $C$. orthopsilosis were $0.03125-8 \mu \mathrm{g} / \mathrm{mL}$ for three susceptible isolates to ketoconazole and one only was resistant $(16 \mu \mathrm{g} / \mathrm{mL})$. Three isolated were itraconazole susceptible, $(0.125 \mu \mathrm{g} / \mathrm{mL})$, and one was dose-dependent $(0.5 \mu \mathrm{g} / \mathrm{mL})$. All isolated were fluconazole susceptible with MIC values of $0.25-2 \mu \mathrm{g} / \mathrm{mL}$ ) and one was resistant to ciclopirox olamine $(1 \mu \mathrm{g} / \mathrm{mL})$. Seven $C$. tropicalis isolates were susceptible to ketoconazole presented MIC values between $0.03125-8 \mu \mathrm{g} / \mathrm{mL}$, while one was resistant $(16 \mu \mathrm{g} / \mathrm{mL})$. Five isolated were fluconazole susceptible with MIC values of $0.0125-8 \mu \mathrm{g} / \mathrm{mL}$, one dose-dependent $(16 \mu \mathrm{g} / \mathrm{mL})$ and there were resistant with MIC

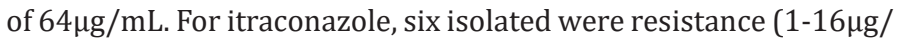
$\mathrm{mL})$ for six isolates, one dose-dependent $(0.5 \mu \mathrm{g} / \mathrm{mL})$ and one was susceptible $(0.03125 \mu \mathrm{g} / \mathrm{mL})$. For ciclopirox olamine, six isolates had MIC between $0.125-0.5 \mu \mathrm{g} / \mathrm{mL}$ and two were between $1-2 \mu \mathrm{g} /$ $\mathrm{mL}$ classified as resistant. All C. albicans isolates were susceptible against ketoconazole fluconazole and ciclopirox olamine. One isolate was resistant $(16 \mu \mathrm{g} / \mathrm{mL})$ and another was dose-dependent $(0.5 \mu \mathrm{g} / \mathrm{mL})$ against itraconazole.

\section{Clinical findings}

Examination of clinical type of onychomycosis was not limited to patients with suspected of onychomycosis, but includes all 
patients attended in the dermatological service with nail changes of various origins with the aim of excluding. Among 108 patients with onychomycosis diagnosed, 60 patients presented distal lateral subungual onychomycosis (DLSO), 26 total dystrophic onychomycosis (TDO) and 22 onychomycosis of mixed pattern (OM). In DLSO patients, Candida spp. were the main etiological agent in 47 patients, followed by Fusarium sp. in 9 patients (Figure 3), T. mentagrophytes in 2 and 1 infection caused by association of Candida sp. and Fusarium sp. TDO cases presented Candida $s p$. as agent in 14 patients, NDFF in 6 patients, being 4 Fusarium sp. 1 Aspergillus niger and 1 Scytalidium dimidiatum (Figure 4), Trichophyton mentagrophytes in 2. Among OM patients, 17 were infected with Candida sp., two were infected by Fusarium sp., one by Candida $s p$. associated with Fusarium $s p$. The patients ' records showed that 52 had been suffering symptoms between 1 to 4 years, 45 between 5 to 10 years and 11 reported clinical symptoms for longer than 10 years. Moreover, 61 patients report they had undergone empirical treatment in the past without success (Table $3)$.

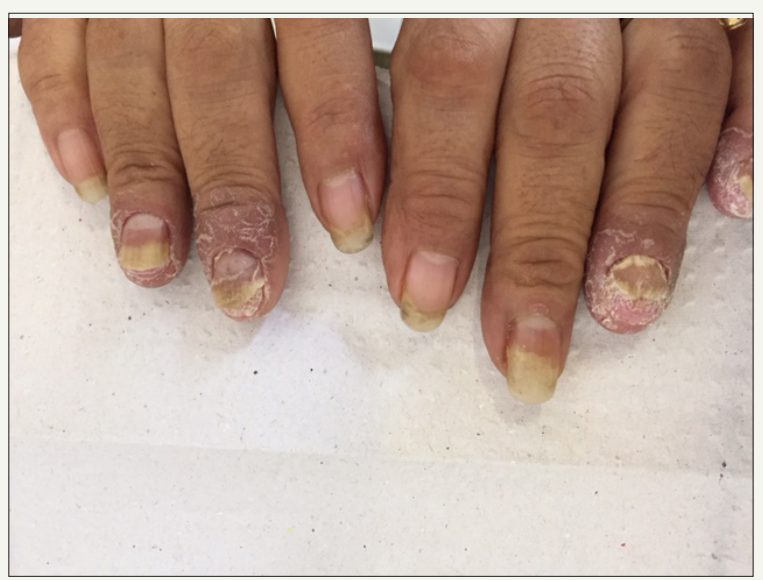

Figure 3: Onychomycosis by Fusarium sp. showing architecture distorted on fingernails.

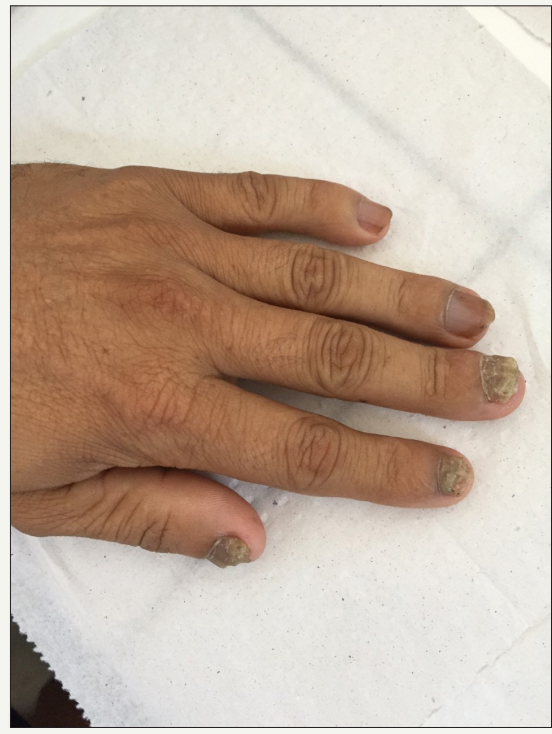

Figure 4: Onychomycosis by Scytalidium dimidiatum characterized by advanced disease involving several nails.

\section{Discussion}

The average age of the patients was 59 years, with the greatest frequency in the 54-64 year range. The higher incidence of the disease in older people is possibly due to the slower nail growth and the greater difficulty of cutting them, as well as the presence of diseases such as diabetes and repeated finger injuries. The disease is uncommon in children, perhaps because of the faster nail growth and smaller size $[6,8,13]$. In Brazil, studies in the cities of Recife, São
Paulo and São José do Rio Preto have identified roughly the same average age and age range, greater prevalence in older people and rare occurrence in children. The results presented here therefore corroborate those findings $[7,8,14]$.

Excessive contact with humidity and exposure to chemical products are considered aggravating factors for the development of onychomycosis. Among the occupations reported by the women in this study, homemaker was most common, and the leading 
anatomical site was the fingernails. The same profile has been found in other areas of Brazil as well as other countries, such as Guatemala, India and United States [7,8,14,15]. With respect to the most common etiological agents, some authors have reported dermatophytes, with T. rubrum being the most common isolate in these studies $[6,15,13]$. In contrast, in this study yeasts of the Candida genus were the most common etiological agents, for both sexes and affected regions. Among the studies that have collected similar data, one descriptive study was conducted in São Paulo $[7,14,16]$, in the wich, proteomic analysis was applied to isolated and purified yeast samples and $100 \%$ were found to be positive for Candida sp., C. albicans is commonly found as a causative agent of onychomycosis, having been observed in one study as the main species among yeasts [14]. In our study, the most prevalent species was $C$. parapsilosis, corroborating the findings of Lone et al. [7] We also identified $C$. tropicalis and $C$. orthopsilosis, both with frequency greater than $C$. albicans, which was identified in three samples. The NDFF formed the second most frequent group, with the most prevalent being Fusarium $s p$, followed by Aspergillus $s p$. and Scytalidium sp. The NDFF have been increasing as agents causing fungal nail infections [13]. The dermatophytes isolated in this study were all of the species T. mentagrophytes, different than in some other studies, which have found T. rubrum as most common $[6,8,15]$. In Brazil, surveys conducted in the states of Rio de Janeiro (2004) and Goiás (2005), city of Recife (2009) and city of São José do Ribeirão Preto (2015) presented the same pattern of causative agents of onychomycosis, while one study, in the city of São Paulo, found T. rubrum to be the main causative agent [7,14-18].

Table 3: In vitro antifungal susceptibility of the non-dermatophytic filamentous fungi isolated from nail scrapings from patients of a public health service unit.

\begin{tabular}{|c|c|c|c|c|c|}
\hline \multirow{2}{*}{ Patient ID Number } & \multirow{2}{*}{ Genus } & \multicolumn{4}{|c|}{$\operatorname{MIC}(\mu \mathrm{g} / \mathrm{mL})$} \\
\hline & & Ketoconazole & Itraconazole & Fluconazole & Terbinafine \\
\hline $11 \mathrm{~A}$ & Aspergillus sp. & 16 & 16 & 64 & $>64$ \\
\hline 94 & Fusarium sp. & 16 & $>16$ & $>64$ & 64 \\
\hline 151 & Fusarium sp. & 4 & 16 & 32 & 64 \\
\hline 260 & Fusarium sp. & 16 & 16 & $>64$ & 64 \\
\hline 442 & Scytalidium dimidiatum & 0.03125 & $>16$ & 32 & $>64$ \\
\hline 670 & Fusarium sp. & 8 & $>16$ & $>64$ & $>64$ \\
\hline 825 & Fusarium sp. & 8 & 16 & $>64$ & $>64$ \\
\hline $879 \mathrm{C}$ & Fusarium sp. & $>16$ & $>16$ & $>64$ & 32 \\
\hline
\end{tabular}

Each species responsible for onychomycosis produces specific lesions on the nail plate. In this study, according to the morphology, we found DLSO with greatest frequency, followed by TDO and OM, while no cases of superficial onychomycosis white or proximal subungual onychomycosis were observed. The lesions characteristic of DLSO are related to infection by dermatophytes, but these characteristics are identical to those of ungual candidiasis, making it hard to differentiate the etiological agent only by the morphological pattern. TDO is considered to be an evolution of the other types, where there is total nail destruction, hyperkeratosis and modification of the surface. The data on the clinical types of onychomycosis in this study are similar to those reported by other researchers but differ regarding the etiological agents/ clinical pattern $[6,13,18,19]$. The data collected in this study show profile of onychomycosis in the Northeast region of Brazil. Greater efforts should be made to inform people about the disease and the resources for its diagnosis and treatment [20-22]. Also, more studies should be conducted to refine the diagnosis and select therapies, since the varied species that cause the disease respond differently to the available drugs.

\section{Acknowledgment}

The authors wish to thank to the Postgraduate National Program (PNPD/UFPE 1277371/2014) for the scholarship of Humberto Gonçalves Bertão.

\section{References}

1. Tchernev G, Penev PK, Nenoff P, Zisova LG, Cardoso JC, et al. (2013) Onychomycosis: modern diagnostic and treatment approaches. Wien Med Wochenschr 163(1-2): 1-12.

2. Kim DM, Suh MK, Ha GY, Sohng SH (2012) Fingernail onychomycosis due to aspergillus niger. Ann Dermatol 24(4): 459-463.

3. Mcauley WJ, Jones AS, Traynor MJ, Guesné S, Murdan S, et al. (2016) An investigation of how fungal infection influences drug penetration trough onychomycosis patients nail plates. Eur J Pharm Biopharm 102: 178184 .

4. Westerberg DP, Voyack MJ (2013) Onychomycosis: current trends in diagnosis and treatment. Am Fam Physician 88(11): 762-770.

5. Chan Hhl, Wong ET, Yeung CK (2014) Psychosocial perception of adults with onychomycosis: a blinded, controlled comparison of 1,017 adult Hong Kong residents with or without onychomycosis. Biopsychosoc Med 8: 15

6. Ghannoum M, Isham N (2014) Fungal nail infections (onychomycosis): a never-ending story? PLoS Pathog 10(6): e1004105.

7. Lone R, Bashir D, Shabirahmad, Syed A, Syedkhurshid (2013) A study on clinico-mycological profile, aetiological agents and diagnosis of onychomycosis at a government medical college hospital in kashmir. J Clin Diagn Res 7(9): 1983-1985.

8. Montarim DTA, Almeida MTG, Colombo Te (2015) Onychomycosiss estudo epidemiológico e micológico no município de são josé do rio preto. J Health Sci Inst 33(2): 118-121.

9. Velasquez AV, cardona AJÁ (2017) Meta-analysis of the utility of culture, biopsy, and direct $\mathrm{KOH}$ examination for the diagnosis of onychomycosis. BMC infectious diseases 17: 166. 
10. Elewski Be, Tosti A (2015) A risk factors and comorbidities for onychomycosis. J Clin Aesthet Dermatol 11(8): 38-42.

11. Limaneto R, Santos C, Lima N, Sampaio P, Pai C, et al. (2014) Application of MALDI-TOF MS for requalification of a candida clinical isolates culture collection brazilian. Braz J Microbiol 45(2): 515-522.

12. CLINICAL LABORATORY STANDARDS INSTITUTE (CLSI). (2008) Reference Method for Broth Dilution Antifungal Susceptobility Testing of Yeasts. Approved standard-3rd edition M27-A3; Wayne, PA, USA Clinical Laboratory Standards Institute.

13. Jesús Silva MA, Fernández Martínez R, Roldán MR, Arenas R ( 2015) Dermoscopic patterns in patients with a clinical diagnosis of onychomycosis-results of a prospective study including data of potassium hydroxide $(\mathrm{KOH})$ and culture examination. Dermatol Pract Concept 5(2): 39-44.

14. Ribeiro CSC, Zaitz C, Framil VMS, Ottoboni TSC, Tonoli MSC, et al. (2015) Descriptive study of onychomycosis in a hospital in são paulo. Braz J Microbiol 46(2): 485-492.

15. Martínez HEO, Arroyo CS, Tejada GDL, Porras LCF, Arenas R (2015) Onychomycosis due to opportunistic molds. An Bras Dermatol 90(3): 334-337.
16. Miranda KC, Araújo CR, Khrais CHA, Lemos JA (2005) Identificação de yeasts do gênero candida nas unhas e em descamação de pele em goiânia (GO), durante o ano de 2003. Revista De Patologia Tropical 34(2): 123-128.

17. Queller JN, Bhatia N (2015) The dermatologist's approach to onychomycosis. J Fungi (Basel) 1(2): 173-184.

18. Araújo JGA, Souza MAJ, Bastos OMP, Oliveira JC (2003) Onychomycosiss por fungos emergentes: análise clínica, diagnóstico laboratorial e revisão. An Bras Dermatol 78(4): 445-455.

19. Lima KM, Delgado M, Rego RSM, Castro CMMB (2008) Candida albicans e candida tropicalis isoladas de onychomycosis em paciente hiv-positivo: co resistência in vitro aos azólicos. Revista De Patologia Tropical 37(1): 57-64.

20. Pajaziti L,Vasili E (2015) Treatment of onychomycosis - a clinical study. Med Arh 69(3): 173-176

21. Leelavathi M, Noorlaily MN (2014) Onychomycosis nailed. Malays Fam Physician 9(1): 2-7.

22. Vasconcelos C, Pereira CQ, Suza MC, Pelegrini A, Freitas RS, et al. (2013) Identification of fungi species in the onychomychosis of institutionalized elderly. An Bras Dermatol 88(3): 377-380.

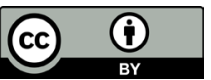

Creative Commons Attribution 4.0 International License

For possible submissions Click Here

\section{Submit Article}

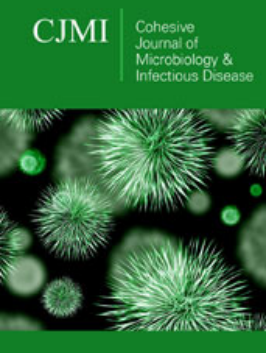

Cohesive Journal of Microbiology \& Infectious Disease Benefits of Publishing with us

- High-level peer review and editorial services

- Freely accessible online immediately upon publication

- Authors retain the copyright to their work

- Licensing it under a Creative Commons license

- Visibility through different online platforms 